\title{
Achieving lipid goals with rosuvastatin compared with simvastatin in high risk patients in real clinical practice: a randomized, open-label, parallel-group, multi-center study: the DISCOVERY-Beta study
}

\author{
Toivo Laks' \\ Ester Keba ${ }^{2}$ \\ Mariann Leiner ${ }^{3}$ \\ Eero Merilind ${ }^{4}$ \\ Mall Petersen ${ }^{5}$ \\ Sirje Reinmets ${ }^{6}$ \\ Sille Väli ${ }^{7}$ \\ Terje Sööt ${ }^{8}$ \\ Karin Otter ${ }^{8}$ \\ 'Clinic of Internal Medicine, \\ North-Estonia Regional Hospital, \\ Tallinn, Estonia; ${ }^{2}$ Clinic of Internal \\ Medicine, Viljandi County Hospital, \\ Viljandi, Estonia; ${ }^{3}$ Mustamäe Family \\ Doctors Centre, Tallinn, Estonia; \\ ${ }^{4}$ Nõmme Family Doctors Centre, \\ Tallinn, Estonia; ${ }^{5}$ Saku Health Centre, \\ Saku, Estonia; ${ }^{6}$ Kristiine Family \\ Doctors, Tallinn, Estonia; ${ }^{7}$ Family \\ Doctor Sille Väli, Kuressaare, Estonia; \\ ${ }^{8}$ AstraZeneca, Tallinn, Estonia
}

\begin{abstract}
The aim of this multi-center, open-label, randomized, parallel-group trial was to compare the efficacy of rosuvastatin with that of simvastatin in achieving the 1998 European Atherosclerosis Society (EAS) lipid treatment goals. 504 patients ( $\geq 18$ years) with primary hypercholesterolemia and a 10-year cardiovascular (CV) risk $>20 \%$ or history of coronary heart disease (CHD) or other established atherosclerotic disease were randomized in a 2:1 ratio to receive rosuvastatin $10 \mathrm{mg}$ or simvastatin $20 \mathrm{mg}$ once daily for 12 weeks. A significantly higher proportion of patients achieved 1998 EAS low-density lipoprotein cholesterol (LDL-C) goal after 12 weeks of treatment with rosuvastatin $10 \mathrm{mg}$ compared to simvastatin $20 \mathrm{mg}$ (64 vs $51.5 \%$, $\mathrm{p}<0.01$ ). Similarly, significantly more patients achieved the 1998 EAS total cholesterol (TC) goal and the 2003 EAS LDL-C and TC goals ( $<0.001$ ) with rosuvastatin $10 \mathrm{mg}$ compared with simvastatin $20 \mathrm{mg}$. The incidence of adverse events and the proportion of patients who discontinued study treatment were similar between treatment groups. In conclusion, in the DISCOVERY-Beta Study in patients with primary hypercholesterolemia greater proportion of patients in the rosuvastatin $10 \mathrm{mg}$ group achieved the EAS LDL-C treatment goal compared with the simvastatin $20 \mathrm{mg}$ group. Drug tolerability was similar across both treatment groups.
\end{abstract}

Keywords: hypercholesterolemia, low-density lipoprotein cholesterol, statins, rosuvastatin, simvastatin, tolerability

\section{Introduction}

Despite a substantial decrease in cardiovascular disease (CVD) mortality over the past 30 years in several industrialized countries, coronary heart disease (CHD) remains the leading cause of morbidity and mortality (Thom 1989; Tunstall-Pedoe et al 2003). The decline in CHD mortality has been accompanied by a simultaneous decrease in the main risk factors. This has led to speculation that during the 1970s the decline in CHD mortality rate was mainly due to primary prevention, but during the 1980s improved treatment and secondary prevention have increasingly contributed to the decrease (Vartiainen et al 1994). At the same time, in most developing countries, the incidence of CVD is increasing towards epidemic levels (Reddy and Yusuf 1998). Also, in Eastern Europe CHD morbidity and mortality rates, particularly among men, are high compared with other areas of Europe (Sans et al 1997). Estonia, an eastern European country and formerly part of the former Soviet Union, has been facing high CVD and CHD rates. In Estonia, CVD and CHD account, respectively, for 55\% and 32\% of all deaths (Estonian Medical Statistical Buerau 1997; Laks et al 1999). The age-standardized mortality rates by the World Health Organization multinational MONItoring of trends and determinants in CArdiovascular disease (WHO MONICA) Project protocol criteria 
for 35- to 64-year-old people per 100,000 population in Estonia ranged from 208 to 317 for men and from 31 to 61 for women, substantially higher than rates in southern and central European centers of the WHO MONICA Project (Laks et al 1999; Tunstall-Pedoe et al 1999).

Findings that an excess of total cholesterol (TC) and low-density lipoprotein cholesterol (LDL-C) particles are the main causes of atherosclerosis and major risk factors for $\mathrm{CHD}$ have been confirmed by molecular biology, animal experiments, and clinical and epidemiological trials (LaRosa et al 1990; Vartiainen et al 1994; Levine et al 1995; Coresh et al 1996). The importance of elevated TC and LDL-C levels are described in many guidelines (Wood et al 1998; Adult Treatment Panel III 2001; De Backer et al 2003). Substantial lowering of LDL-C level has been associated with risk reduction and a reduction in CHD events (de Lorgeril et al 1999; Ito et al 2001). Despite the introduced guidelines and the availability of lipid-lowering therapies (LLT), many patients fail to meet TC and LDL-C goals (Pearson et al 2000). Results from large-scale trials have confirmed the effectiveness of the 3-hydroxy-3-methylglutaryl coenzyme A (HMG-CoA) reductase inhibitors (statins) in the primary and secondary prevention on CHD. However, the residual morbidity and mortality remains high (Gotto and Grundy 1999). Therefore, the development of more effective lipid-lowering drugs has potential to further improve $\mathrm{CV}$ risk reduction.

The DIrect Statin COmparison of LDL-C Values: an Evaluation of Rosuvastatin therapY (DISCOVERY) Study was series of 9 independently powered studies performed in different countries and regions worldwide, including: The Netherlands (Bots and Kastelein 2005); Triple Country - Iceland, Ireland, Finland (Strandberg et al 2004); Asia (Zhu et al 2007); Alpha - Eastern Europe, Central and South Africa, the Middle East (Binbrek et al 2006); Belux - Belgium, Luxembourg (Herregods et al 2006); Canada (Gupta and Constance 2005); Penta - Latin America, Portugal (Fonseca et al 2005); Beta (Estonia); and the United Kingdom (Middleton and Fuat 2006). These studies aimed to compare the efficacy of rosuvastatin $10 \mathrm{mg}$ with that of other statins (given at their respective recommended starting doses) in achieving recommended lipid levels in the clinical setting. Simvastatin $20 \mathrm{mg}$ was chosen as the comparator, because it was the standard of care in Estonia at the time of the start of the study. The DISCOVERY study program started in March 2002. The primary objective of this trial was to provide the results for the DISCOVERY-Beta Study, which compared the efficacy of rosuvastatin $10 \mathrm{mg}$ with that of simvastatin $20 \mathrm{mg}$ to achieve the 1998 European
Atherosclerosis Society (EAS) LDL-C treatment goal (Wood et al 1998). The 1998 EAS LDL-C goal served as primary endpoint in the Discovery series studies, making it possible to use the data for the meta-analysis of the series.

\section{Methods}

\section{Trial design and patients}

The DISCOVERY-Beta was a 12-week multi-center, openlabel, randomized, parallel-group study conducted between March and September 2004 at 18 centers in Estonia. Men and women (aged $\geq 18$ years) were enrolled with primary hypercholesterolemia (LDL-C $>3.5 \mathrm{mmol} / \mathrm{L}$ if statin-naïve or $>3.1 \mathrm{mmol} / \mathrm{L}$ if switching) and a 10 -year CV risk $>20 \%$ or a history of CHD or other established atherosclerotic disease (cerebrovascular disease as transient ischemic attack, ischemic stroke, or carotid artery disease; CHD as acute myocardial infarction [AMI], unstable angina, or coronary revascularization; peripheral arterial disease $[\mathrm{PAD}]$ as aortic aneurysm, intermittent claudication, lower limb arterial revascularization, or amputation due to the complications of atherosclerosis) and fasting triglycerides (TG) $\leq 4.52 \mathrm{mmol} / \mathrm{L}$ at visit 2 (week 0). Subjects were selected by cardiologists, internists, and general practitioners (when needed if previously consulted by cardiologist) from a primary or secondary prevention subject population. Statin-naïve subjects (those who had not received a statin within the previous 6 months) or subjects on a start dose (commonly used or accepted starting doses were atorvastatin $10 \mathrm{mg}$, fluvastatin $20 \mathrm{mg}$, or pravastatin $20 \mathrm{mg}$ ) or other LLT, which was ineffective (ie, subjects had not reached their LDL-C goal at that dose), were entered into this study. Dietary counseling for 6 weeks was given for statin-naïve patients before enrolling into the study. Main exclusion criteria were: known familial hypercholesterolemia; secondary dyslipidemia of any cause; history of serious adverse effect (SAE) or hypersensitivity to other HMG-CoA reductase inhibitors; pregnancy, breastfeeding, and women of childbearing potential not using chemical or mechanical contraception or with a positive pregnancy test; malignancy; use of disallowed concomitant medications (antibiotics clarithromycin or erythromycin, antifungal treatment with fluconazole, ketoconazole, or itraconazole, lipid-lowering agents, cyclosporin); history of alcohol or drug dependence; active liver disease or hepatic dysfunction with elevations of alanine aminotransferase $($ ALT) or aspartate aminotransferase $($ AST) $>1.5$ times upper limit of normal (ULN); renal impairment as defined by serum creatinine $>220 \mu \mathrm{mol} / \mathrm{L}(2.5 \mathrm{mg} / \mathrm{dL})$; uncontrolled diabetes; unstable angina; uncontrolled hypertension as either 
diastolic $>95 \mathrm{mmHg}$ or systolic blood pressure $>200 \mathrm{mmHg}$; unexplained serum creatine kinase $(\mathrm{CK})>3$ times ULN; subjects in serious or unstable medical or psychological condition that compromises the subject safety or participation in the trial. Investigators of each center ensured that each patient gave written informed consent for participation in the study.

Patients were assessed for eligibility and, within 2 weeks, were randomized in a 2:1 ratio to receive rosuvastatin $10 \mathrm{mg}$ or simvastatin $20 \mathrm{mg}$ administered once daily for 12 weeks. Patients were allocated numbers as they entered the study, and a computer-generated randomization scheme was used to determine treatment allocation as each patient became eligible. Treatment codes for each patient were provided to each center in a sealed envelope, and investigators were unaware of the randomization scheme and treatment codes until the envelope was opened at the randomization visit.

\section{Efficacy and tolerability assessments}

At each visit (screening at week -2 , randomization at week 0 , final at week 12) blood samples were drawn to determine serum levels of TC, LDL-C, high-density lipoprotein cholesterol (HDL-C), and TG. Local laboratories were used in the study. Serum LDL-C level was determined using the Friedewald formula (Friedewald et al 1972). Patients with $\mathrm{TG} \geq 4.52 \mathrm{mmol} / \mathrm{L}$ were excluded from the study, so that the confounding effect of elevated TG level on the Friedewald formula was minimized.

The primary endpoint was the percentage of patients achieving the 1998 EAS LDL-C goal ( $<3.0 \mathrm{mmol} / \mathrm{L})$ at week 12. Secondary efficacy endpoints included: 1 . percentage of patients achieving the $1998 \mathrm{EAS}$ TC goal $(<5.0 \mathrm{mmol} / \mathrm{L})$; 2. percentage change from pre-dose and final visit in serum LDL-C, TC, HDL-C, and TG levels in statin-naïve and switched patients; 3 . comparing the efficacy of rosuvastatin $10 \mathrm{mg}$ with simvastatin $20 \mathrm{mg}$ by assessment of percentage of subjects who reach the 2003 EAS LDL-C $(<2.5 \mathrm{mmol} / \mathrm{L})$ or TC $(<4.5 \mathrm{mmol} / \mathrm{L})$ target goals for patients with clinically established CVD and/or diabetes mellitus (DM) after 12 weeks of therapy; 4. comparison of rosuvastatin $10 \mathrm{mg}$ with simvastatin $20 \mathrm{mg}$ after 12 weeks of treatment for the incidence and severity of adverse events (AEs) and abnormal laboratory values. Lipid levels were determined from fasting (12 hours) blood samples analyzed in local laboratories. The incidence and severity of AEs, including abnormal laboratory values (liver enzymes, creatinine, CK) were recorded to assess tolerability. At every visit, AEs were reported to investigators in response to a standard questionnaire.
Any decline in a patient's condition subsequent to study entry was considered an AE. Also, the relationship of SAEs to the treatment was assessed.

\section{Statistical analysis}

The trial has been sized to detect a difference of $15 \%$ between rosuvastatin $10 \mathrm{mg}$ and simvastatin $20 \mathrm{mg}$, in terms of the percentage of subjects reaching the 1998 EAS LDL-C target goal at week 12 . Using these data, and the fact that patients were randomized in a $2: 1$ ratio (rosuvastatin : simvastatin), it was calculated that 480 evaluable subjects were required to achieve $90 \%$ power for a two-sided significance level of $5 \%$. Subjects were evaluated based on an intention to treat (ITT) population which consisted of subjects who had a baseline reading, one week 12 reading, and at least one dose of medication. If a subject was withdrawn prior to week 12 , the last value after baseline was taken as the week 12 assessment. The numbers of subjects reaching the 1998 EAS lipid target goals on rosuvastatin $10 \mathrm{mg}$ and simvastatin $20 \mathrm{mg}$ at week 12 were compared using a logistic regression analysis with factors being fitted for treatment, subject type (naïve or switched) and the pre-dose lipid parameter value fitted as a covariate. For lipid parameters, analyses of percentage change for pre-dose (week 0 ) and at week 12 were performed separately for the naïve and switched patients because the week 0 value for statin-naïve patients followed 6 weeks of dietary advice, whereas this was not case for switched patients. The analyses were performed using the ANCOVA model, with factors fitted for treatment and the pre-dose (week 0) lipid parameter value as a covariate. The results are presented as least squares means (LSM) and the difference between the LSM, with $\mathrm{p}$ values and associated $95 \%$ confidence intervals. In addition, the percentage change in lipid parameters has been summarized.

\section{Results}

\section{Patient characteristics}

Of 586 patients screened, 504 (59.3\% women and 40.7\% men) were randomized at visit 2 (week 0 ) into the treatment groups (rosuvastatin $10 \mathrm{mg} 334$ and simvastatin $20 \mathrm{mg}$ 170 patients) and received at least 1 dose of the study drug, and had baseline and week 12 lipid measurements available (ITT population). Eighty-two patients were discontinued before randomization: in 73 subjects eligibility criteria were not fulfilled, 1 subject ALT was elevated $>3$ times ULN, and 8 subjects withdrew their consent (Figure 1) .

Baseline demographic, clinical characteristics, risk factors, and previous LLT for 504 randomized patients are 


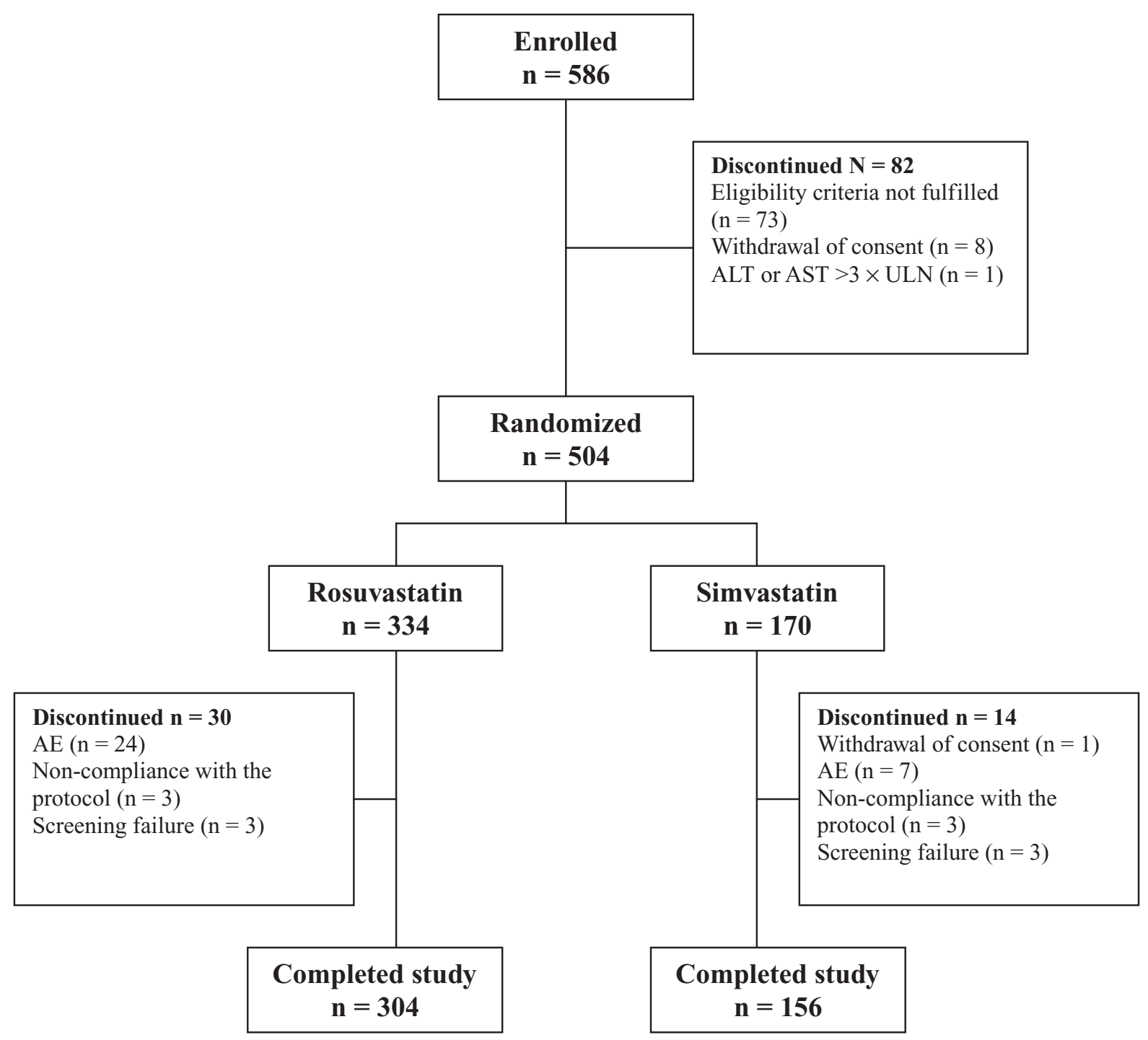

Figure I Patient disposition in study groups.

Abbreviations: AE, adverse event; ALT, alanine aminotransferase; AST, aspartate aminotransferase; ULN, upper limit of normal.

presented in Table 1. Sex distribution, clinical characteristics of study subjects, and frequency of risk factors (body mass index [BMI], systolic and diastolic blood pressure [BP], documented atherosclerotic disease, type $2 \mathrm{DM}$, family history of premature CHD and PAD, smoking, low HDL or elevated TG) were similar between the two treatment groups. In total, 187 (37.1\%) patients had documented atherosclerotic disease, 115 (22.8\%) type 2 DM, 98 (19.4\%) family history of premature CHD or PAD, 25 (5.0\%) low HDL, 208 (41.3\%) elevated TG, and 167 (33.1\%) were smokers. 119 (23.6\%) of the total study population had previously received LLT, 82 patients $(24.6 \%)$ in the rosuvastatin group compared with $37(21.8 \%)$ patients in the simvastatin group. The most frequently prescribed LLTs were pravastatin (60 patients, $11.9 \%$ ) and atorvastatin (29 patients, 5.8\%).

\section{Efficacy}

The proportions of patients reaching the 1998 EAS LDL-C goal (primary endpoint), the 1998 and 2003 EAS TC, and the 2003 EAS LDL-C goals (all secondary endpoints) after 12 weeks of treatment with either rosuvastatin $10 \mathrm{mg}$ or simvastatin $20 \mathrm{mg}$ are presented in Table 2. Significantly more patients in the rosuvastatin group achieved the 1998 EAS LDL-C goal compared with those in the simvastatin group, $210(64 \%)$ and $86(51.5 \%)$ patients $(\mathrm{p}<0.01)$. In addition, significantly more statin-naïve subjects achieved the goal in the rosuvastatin arm compared with simvastatin, $165(67.1 \%)$ versus $71(54.6 \%)$ patients $(\mathrm{p}<0.001)$. The same trend occurred within switched patients $45(54.9 \%)$ patients in the rosuvastatin group compared to 15 (40.5\%) patients in the simvastatin group. A significantly higher 
Table I Baseline demographic and clinical characteristics of the study population was statistically not different in the two treatment groups

\begin{tabular}{|c|c|c|}
\hline Characteristic & Rosuvastatin $(n=334)$ & Simvastatin $(n=170)$ \\
\hline Age, y (SD) & $62.9(9.4)$ & $63.9(9.7)$ \\
\hline \multicolumn{3}{|l|}{ Sex, no (\%) } \\
\hline Female & $200(59.9)$ & $99(58.2)$ \\
\hline Male & I $34(40.1)$ & $71(4 I .8)$ \\
\hline $\mathrm{BMI}, \mathrm{kg} / \mathrm{m}^{2}(\mathrm{SD})$ & $29.6(4.7)$ & $28.8(4.7)$ \\
\hline \multicolumn{3}{|l|}{$\mathrm{BP}, \mathrm{mmHg}(\mathrm{SD})$} \\
\hline Systolic & $147.6(19.2)$ & $148.4(19.6)$ \\
\hline Diastolic & $84.7(8.5)$ & $84.3(8.0)$ \\
\hline \multicolumn{3}{|l|}{ Risk factors, no. (\%) } \\
\hline Atherosclerosis ${ }^{\mathrm{a}}$ & $122(36.5)$ & $65(38.2)$ \\
\hline Type 2 DM & 79 (23.7) & $36(21.2)$ \\
\hline \multicolumn{3}{|l|}{ Family history of } \\
\hline premature $\mathrm{CHD}$ or $\mathrm{PAD}^{\mathrm{a}}$ & $64(19.2)$ & $34(20.0)$ \\
\hline Current smoking & $112(33.5)$ & $55(32.4)$ \\
\hline Low HDL ( $\leq 0.9 \mathrm{mmol} / \mathrm{L})$ & $16(4.8)$ & $9(5.3)$ \\
\hline Elevated TG $(\geq 2.0 \mathrm{mmol} / \mathrm{L})$ & $139(4 \mid .6)$ & $69(40.6)$ \\
\hline Switched from previous LLT, no. (\%) & $82(24.6)$ & $37(21.8)$ \\
\hline Rosuvastatin & $\mathrm{I}(0.3)$ & $0(0)$ \\
\hline Simvastatin & $15(4.5)$ & $8(4.7)$ \\
\hline Atorvastatin & $18(5.4)$ & II (6.5) \\
\hline Pravastatin & $43(12.9)$ & $17(10.0)$ \\
\hline Other LLT (fibrates) & $5(1.5)$ & $\mathrm{I}(0.6)$ \\
\hline
\end{tabular}

aDefined as

I) Patients with a history of transient ischemic attacks (TIA) or ischemic stroke, carotid artery disease as evidenced by a history carotid endarterectomy, angioplasty, or other cerebral revascularization. Patients with advanced (at least $60 \%$ stenosis) atherosclerosis in the common or internal carotid artery documented (by angiography or ultrasound) will also be eligible.

2) Patients with coronary artery disease, defined by a history of myocardial infarction or hospitalization for treatment of unstable angina, angina pectoris corroborated by objective evidence of myocardial ischemia, coronary revascularization or angiographic evidence of stenosis $>50 \%$ in one or more major epicardial coronary artery.

3) Patients with peripheral arterial disease defined by a history of aortic aneurysm repair, aorto-iliac, femoral or other arterial surgery or angioplasty performed to relieve lower limb ischemia, lower limb amputation performed due to complications of atherosclerotic arterial disease, or, intermittent claudication with an ankle-brachial pressure index $(\mathrm{ABI})<0.9$.

Abbreviations: CHD, coronary heart disease; HDL, high density lipoprotein; LLT, lipid-lowering therapies; PAD, peripheral arterial disease; TG, fasting triglycerides.

number of patients in the rosuvastatin group achieved the 1998 EAS TC goal compared with patients in simvastatin arm, $195(59.5 \%)$ versus $72(43.1 \%)$ patients $(\mathrm{p}<0.001)$. This analysis was made within the total ITT population, as there was no significant difference between statin-naïve and switched subjects. Similarly, a significantly greater number of patients receiving rosuvastatin $10 \mathrm{mg}$ reached the 2003 EAS LDL-C and TC goals compared with patients in the simvastatin group, $146(44.5 \%)$ and $37(22.2 \%)$ patients $(\mathrm{p}<0.001)$ and $141(43 \%)$ and $43(25.7 \%)$ patients $(\mathrm{p}<0.001)$.

Table 2 Subjects (\%) reaching the 1998 and the 2003 EAS lipid (mmol/L) target goals at the end of the study (week I2)

\begin{tabular}{|c|c|c|c|}
\hline Target LDL-C and TC & $\begin{array}{l}\text { Rosuvastatin } \\
\mathrm{n}=328\end{array}$ & $\begin{array}{l}\text { Simvastatin } \\
n=167\end{array}$ & \\
\hline I998 EAS LDL-C < 3.0 & $210(64.0)$ & $86(51.5)$ & $\mathrm{P}<0.0 \mathrm{I}$ \\
\hline 1998 EASTC $<5.0$ & $195(59.5)$ & $72(43.1)$ & $\mathrm{p}<0.00 \mathrm{I}$ \\
\hline \multicolumn{4}{|l|}{2003 EAS LDL-C $<3.0$ or $<2.5$} \\
\hline with established CVD or DM & I $46(44.5)$ & $37(22.2)$ & $\mathrm{P}<0.00 \mathrm{I}$ \\
\hline \multicolumn{4}{|l|}{2003 EASTC $<5.0$ or $<4.5$} \\
\hline with established CVD or DM & $|4|(43.0)$ & $43(25.7)$ & $\mathrm{p}<0.001$ \\
\hline
\end{tabular}

Abbreviations: CVD, cardiovascular disease; DM, diabetes mellitus; EAS, european atherosclerosis society; LDL-C, low-density lipoprotein cholesterol; TC, total cholesterol. 
Percentage change from baseline levels of LDL-C, TC, HDL-C, and TG in both statin-naïve and switched patients are shown in Table 3.

In both treatment groups, in statin-naïve and switched subjects, TG levels declined from baseline, but these decreases were too small to be significant. At the same time, during the 12-week treatment period there were no changes in HDL-C levels in statin-naïve patients in the rosuvastatin and simvastatin groups, and changes in switched patients were small.

\section{Safety}

The occurrence of AEs was similar between groups. Both study statin treatments (rosuvastatin and simvastatin) were generally well tolerated, and the incidence of AEs and SAEs was low. The proportion of patients who discontinued study treatment because of AEs did not differ statistically - in the rosuvastatin group $7.2 \%$ and in the simvastatin group $4.1 \%$ (Table 4). The most common AEs leading to withdrawal from the study were gastrointestinal disorders such as abdominal pain and nausea, and the musculoskeletal disorder myalgia. SAEs were reported by $1.8 \%$ of study subjects. The only death (due to AMI) during the trial was in the rosuvastatin group, and was considered by the investigator to have been unrelated to the investigational product. All SAEs were judged by the investigators as having had no causal relationship to the study treatment, with the one exception of general discomfort (not related to myalgia) reported by a patient receiving simvastatin. The most common AE was nausea, in 13 patients (3.9\%) in the rosuvastatin group and in 6 patients $(3.5 \%)$ in simvastatin group. Myalgia, a known side effect of statin therapy, had a statistically not significant tendency to be reported more frequently with rosuvastatin - by 10 patients (3\%) compared with 1 patient $(0.6 \%)$ in simvastatin group. None of these reports were associated with a clinically significant increase in CK $(>10$ times ULN). Rhabdomyolysis occurred in none of the patients. Mean changes from baseline in circulating levels of ALT, CK, and creatinine at week 12 were small and similar between the rosuvastatin and simvastatin groups, and generally unremarkable. Only 1 patient from each group had a $\mathrm{CK}$ level at week 12 of special note ( $>3$ times ULN).

Subjects with multiple AEs in the same category are counted only once in that category; subjects with AEs $>1$ category are counted once in each category.

\section{Discussion}

CVD is major health problem and a leading cause of global mortality (Thom 1989; Sans et al 1997; Reddy and Yusuf 1998; Tunstall-Pedoe et al 2003). Despite the decline in CHD mortality during recent decades in most Western countries, it remains high because of the aging population

Table 3 Changes in lipid profiles before and after 12 weeks treatment with rosuvastatin $10 \mathrm{mg}$ and simvastatin $20 \mathrm{mg}$

\begin{tabular}{|c|c|c|c|c|c|c|c|c|c|}
\hline \multirow[b]{2}{*}{ Lipid } & \multicolumn{4}{|c|}{ Rosuvastatin $n=334$} & \multicolumn{5}{|c|}{ Simvastatin $n=170$} \\
\hline & $\mathbf{n}$ & $\begin{array}{l}\text { Baseline } \\
\text { Mean } \\
\text { mmol/L }\end{array}$ & $\begin{array}{l}\text { I } 2 \text { weeks } \\
\text { LSM } \\
\mathrm{mmol} / \mathrm{L}\end{array}$ & $\begin{array}{l}\% \Delta \\
\text { Mean } \\
(\mathrm{SE})\end{array}$ & $\mathbf{n}$ & $\begin{array}{l}\text { Baseline } \\
\text { Mean } \\
\text { mmol/L }\end{array}$ & $\begin{array}{l}\text { I } 2 \text { weeks } \\
\text { Mean } \\
\text { mmol/L }\end{array}$ & $\begin{array}{l}\% \Delta \\
\text { LSM } \\
\text { (SE) }\end{array}$ & p value ${ }^{a}$ \\
\hline LDL-C Total & 334 & 4.73 & 2.83 & $-38.79(1.27)$ & 170 & 4.66 & 3.12 & $-32.03(1.37)$ & $<0.001$ \\
\hline Statin-naïve & 252 & 4.87 & 2.72 & $-42.94(0.001)$ & 133 & 4.73 & 3.09 & $-34.20(0.01)$ & $<0.000$ I \\
\hline Switched & 82 & 4.27 & 3.06 & $-26.39(0.03)$ & 37 & 4.39 & 3.21 & $-24.42(0.03)$ & NS \\
\hline TC Total & 334 & 7.13 & 4.89 & $-30.4 \mathrm{I}(0.88)$ & 170 & 7.00 & 5.18 & $-25.27(1.09)$ & $<0.01$ \\
\hline Statin-naïve & 252 & 7.33 & 4.83 & $-33.42(0.01)$ & 133 & 7.07 & 5.13 & $-27.08(0.01)$ & $<0.000$ I \\
\hline Switched & 82 & 6.51 & 5.06 & $-21.40(0.02)$ & 37 & 6.76 & 5.36 & $-18.9 \mid(0.02)$ & NS \\
\hline HDL-C Total & 334 & 1.46 & 1.45 & $+0.66(1.14)$ & 170 & 1.41 & 1.43 & $+2.26(1.47)$ & NS \\
\hline Statin-naïve & 252 & $\mathrm{I} .47$ & $\mathrm{I} .47$ & $+0.01(0.01)$ & 133 & $\mathrm{I} .40$ & 1.40 & $+0.02(0.02)$ & NS \\
\hline Switched & 82 & 1.39 & 1.34 & $-0.01(0.02)$ & 37 & 1.43 & 1.47 & $+0.03(0.03)$ & NS \\
\hline TG Total & 334 & 1.90 & 1.51 & $-14.47(1.86)$ & 170 & 1.92 & 1.61 & $-14.43(2.45)$ & NS \\
\hline Statin-naïve & 252 & 1.92 & 1.50 & $-14.83(0.02)$ & 133 & 1.88 & 1.50 & $-16.82(0.03)$ & NS \\
\hline Switched & 82 & 1.87 & 1.53 & $-13.39(0.02)$ & 37 & 2.06 & 1.92 & $-6.03(0.06)$ & NS \\
\hline
\end{tabular}

${ }^{a} \mathrm{p}$, rosuvastatin vs simvastatin.

Abbreviations: LSM, least squares means; SE, standard error; LDL-C, low-density lipoprotein cholesterol; HDL-C, high-density lipoprotein cholesterol TC, total cholesterol; TG, fasting triglycerides. 
Table 4 Adverse events in rosuvastatin and simvastatin treatment groups (\%)

\begin{tabular}{lll}
\hline Category of AEs & $\begin{array}{l}\text { Rosuvastatin } \\
\mathbf{n = 3 3 4}\end{array}$ & $\begin{array}{l}\text { Simvastatin } \\
\mathbf{n}=170\end{array}$ \\
\hline Any adverse event & $67(20)$ & $37(2 \mathrm{I} .8)$ \\
Serious adverse events & $4(\mathrm{I} .2)$ & $5(2.9)$ \\
Led to death & $\mathrm{I}(0.3)$ & $0(0)$ \\
Led to treatment & $24(7.2)$ & $7(4.1)$ \\
discontinuation & & \\
Most common AEs & & \\
Nausea & $13(3.9)$ & $6(3.5)$ \\
Myalgia & $10(3.0)$ & $1(0.6)$ \\
Diarrhea & $5(I .5)$ & $2(I .2)$ \\
Headache & $4(I .2)$ & $2(I .2)$ \\
AMI & $4(I .2)$ & $0(0)$ \\
\hline
\end{tabular}

Abbreviations: $\mathrm{AE}$, adverse events; $\mathrm{AMI}$, acute myocardial infarction.

(Sleight 2003). CVD includes CHD, and is most frequently caused by atherosclerosis, a progressive condition that may remain asymptomatic for many years, with sudden death often being the first clinical manifestation (Thaulow et al 1993). Elevated LDL-C is an important contributory factor to development of atherosclerosis, and as such is recognized as a major risk factor for CHD. Consequently, LDL-C is a key therapeutic target for the prevention of CHD, with statins recommended as first-line drug treatment (Adult Treatment Panel III 2001; De Backer et al 2003).

This randomized, multi-center study comparing lipidmodifying efficacy of two statins showed that on the basis of both the 1998 EAS and the stricter 2003 EAS LDL-C goals, rosuvastatin showed greater efficacy in reducing LDL-C compared with simvastatin with commonly used starting doses (rosuvastatin $10 \mathrm{mg}$ and simvastatin $20 \mathrm{mg}$ once a day) over 12 weeks of treatment in patients with primary hypercholesterolemia. Also, up to the end of the study, more hypercholesterolemic patients in the rosuvastatin group achieved a reduction in TC levels to the EAS target goals (Wood et al 1998; De Backer 2003) compared with simvastatin-treated patients. Our study confirms the results of previous trials comparing the efficacy of different statins, that rosuvastatin, at a commonly used starting dose, is highly effective in reducing LDL-C levels. Thus, in the DISCOVERY-Beta Study as in the earlier published MERCURY I (Schuster et al 2004), STELLAR (Jones et al 2003), and Rosuvastatin Study Group trials (Brown et al 2002), rosuvastatin was more effective than other statins used (atorvastatin, simvastatin, pravastatin) in decreasing LDL-C levels and allowing more patients to achieve the recommended treatment goals. This effect was evident from week 6 and continued to at least week 52 during the LLT.

The DISCOVERY-Beta Study randomized a large proportion of patients $(24 \%)$ who had not reached the EAS lipid goals with LLTs. At the same time the reduction of LDL-C in statin-naïve patients with rosuvastatin $10 \mathrm{mg}$ was significantly higher than with simvastatin $20 \mathrm{mg}$ ( $43 \%$ and $34 \%$, respectively).

HDL-C has taken on increased importance as a clinical prognostic factor for CVD, which is reflected in coronary preventive guidelines (Wood et al 1998; Adult Treatment Panel III 2001; De Backer et al 2003). In our study analysis of the data from the fixed-dose treatment period, comparing rosuvastatin $10 \mathrm{mg}$ with simvastatin $20 \mathrm{mg}$ did not reveal any changes in HDL-C levels in both groups during the 12 weeks. The reasons could be the relatively high baseline values for HDL-C in both groups and/or some technical issues caused by the fact that local laboratories instead of one central laboratory were used for sample analysis. No definitive or primary reference methods exist for the separation of HDL, and because differences in the precipitation procedures can alter the population of particles precipitated, not all methods give the same result for HDL cholesterol, and therefore standardization of HDL cholesterol measurement is difficult (Marques-Vidal et al 1999). However, questions remain as to the specificity of these assays under contrasting conditions of high and low LDL levels as typically observed in statin trials.

In our study rosuvastatin $10 \mathrm{mg}$ was as effective as simvastatin $20 \mathrm{mg}$ at reducing TG in both statin-naïve and switched patients, confirming results obtained with rosuvastatin $10 \mathrm{mg}$ in earlier published reports (Brown et al 2002; Davidson et al 2002; Jones et al 2003; Binbrek et al 2006). In the DISCOVERY-Beta Study, both rosuvastatin $10 \mathrm{mg}$ and simvastatin $20 \mathrm{mg}$ were well tolerated, with similar profiles of AEs reported with both agents. There appeared to be no differences between treatment groups. The types and numbers of AEs and overall safety profile were consistent with those reported for statin therapy (Knopp 1999; Schuster 2003). However, in our study we found no reports of myopathy or rhabdomyolysis, and rate of myalgia was low in both groups. Treatment discontinuation was similar in both arms of the study; however, in the rosuvastatin group there were 4 cases of AMI which were deemed by the investigators to be unrelated to the investigated product. Significant elevation in liver enzymes was similarly rare in both groups in both treatment populations. 


\section{Limitations}

Because of the open-label design of the study, patient reporting of AEs could have been affected by their awareness of drug treatment or expectations from previous experiences with statins. However, the number and nature of AEs were generally consistent with those observed in previous trials. At the same time, the 12-week study period was long enough to demonstrate the LDL-C reducing effect and possible AEs of statin therapy (Brown et al 2002; Olsson et al 2002).

In conclusion, in the DISCOVERY-Beta Study in patients with primary hypercholesterolemia and high risk of CVD in clinical practice, greater reduction in LDL-C and TC levels was achieved with rosuvastatin $10 \mathrm{mg}$ compared with simvastatin $20 \mathrm{mg}$, with more patients achieving the 1998 EAS and the 2003 EAS LDL-C and TC goals. Both statin treatments were well tolerated.

\section{Acknowledgment}

We gratefully acknowledge the investigators, co-investigators (see Appendix), study coordinators, and the patients who participated in the trial.

\section{Disclosures}

TS and KO are employees of AstraZeneca, Estonia. None of the other authors any conflicts of interest to disclose.

\section{References}

Binbrek AS, Elis A, Al-Zaibag M, et al; for the DISCOVERY Alpha Study Group. 2006. Rosuvastatin versus atorvastatin in achieving lipid goals in patients at high risk for cardiovascular disease in clinical practice: a randomized, open-label, parallel-group, multicenter study (DISCOVERY Alpha Study). Curr Ther Res, 67:21-43.

Bots AFE, Kastelein JJP. 2005. Achieving lipid goals in real life: the Dutch DISCOVERY Study. Int J Clin Pract, 59:1387-94.

Brown WV, Bays HE, Hassmann DR, et al. for the Rosuvastatin Study Group. 2002. Efficacy and safety of rosuvastatin compared with pravastatin and simvastatin in patients with hypercholesterolemia: a randomized, double-blind, 52-week trial. Am Heart J, 144:1036-43.

Coresh J, Kwiterovich PO Jr. 1996. Small, dense low-density lipoprotein particles and coronary heart disease risk: a clear association with uncertain implications. JAMA, 276:914-5.

Davidson M, Ma P, Stein EA, et al. 2002. Comparison of effects on lowdensity lipoprotein cholesterol and high-density lipoprotein cholesterol with rosuvastatin versus atorvastatin in patients with type IIa or IIb hypercholesterolemia. Am J Cardiol, 89:268-75.

De Backer G, Ambrosioni E, Borch-Johansen K, et al. for the Third Joint Task Force of European and Other Societies on Cardiovascular Disease Prevention in Clinical Practice. 2003. Europen guidelines on cardiovascular disease prevention in clinical practice. Eur Heart $J$, 24:1601-10.

de Lorgeril M, Salen P, Martin J-L, et al. 1999. Mediterranean diet, traditional risk factors, and the rate of cardiovascular complications after myocardial infarction: final report of the Lyon Diet Heart Study. Circulation, 99:779-85.

Estonian Medical Statistics Bureau. 1997. Some facts about health care in Estonia 1992-1996. Tallinn, p 64.
Executive Summary of the Third Report of the National Cholesterol Education Program (NCEP) Expert Panel on Detection, Evaluation, and Treatment of High Blood Cholesterol in Adults (Adult Treatment Panel III). 2001. JAMA, 285:2486-97.

Fonseca FAH, Ruiz A, Silva JM, et al. 2005. The DISCOVERY PENTA study: a DIrect Statin COmparison of LDL-C Value - an Evaluation of Rosuvastatin therapY compared with atorvastatin. Curr Med Res Opin, 21:1307-15.

Friedewald WT, Levy RI, Fredrickson DS. 1972. Estimation of the concentration of low-density lipoprotein cholesterol in plasma, without use of the preparative ultracentrifuge. Clin Chem, 18: 499-502.

Gotto AM Jr, Grundy SM. 1999. Lowering LDL cholesterol: questions from recent meta-analyses and subset analyses of clinical trial data: issues from the Interdisciplinary Council on Reducing the Risk for Coronary Heart Disease, ninth Council meeting. Circulation, 99: E1-E7.

Gupta M, Constance C. 2005. Direct statin comparison of LDL-C values: an evaluation of rosuvastatin therapy (DISCOVERY - Canada). [abstract]. Atheroscler Suppl, 6:108.

Herregods MC, Daubresse JC, Michel G, et al. 2006. DISCOVERY BELUX: An open-label, randomised, multi-centre, phase IIIb, parallel group study to compare the efficacy and safety of rosuvastatin and atorvastatin in subjects with type IIa and IIb hypercholesterolaemia. Acta Cardiol, 61:235-6.

Ito MK, Delucca GM, Aldridge MA. 2001. The relationship between lowdensity lipoprotein cholesterol goal attainment and prevention of coronary heart disease related events. J Cardiovasc Pharmacol Ther, 6:129-35.

Jones PH, Davidson MH, Stein EA, et al; for the STELLAR Study Group. 2003. Comparison of efficacy and safety of rosuvastatin versus atorvastatin, simvastatin, and pravastatin across doses (STELLAR Trial). Am J Cardiol, 92:152-60.

Knopp RH. 1999. Drug treatment of lipid disorders. N Engl J Med, 341:498-511.

Laks T, Tuomilehto J, Jõeste E, et al. 1999. Alarmingly high occurrence and case fatality of acute coronary heart disease events in Estonia: results from the Tallinn AMI register 1991-94. J Int Med, 246:53-60.

LaRosa JC, Hunninghake D, Bush D, et al; for the Task Force on Cholesterol Issues, American Heart Association. 1990. The cholesterol facts: a summary of the evidence relating dietary fats, serum cholesterol, and coronary heart disease: a joint statement by the American Heart Association and the National Heart, Lung, and Blood Institute. Circulation, 81:1721-33.

Levine GN, Keaney JF Jr, Vita JA. 1995. Cholesterol reduction in cardiovascular disease: clinical benefits and possible mechanisms. $N$ Engl $J$ Med, 332:512-21.

Marques-Vidal P, Ferrario P, Kuulasmaa K, et al; for the WHO MONICA Project. 1999. Quality Assessment of Data on HDL Cholesterol in the WHO MONICA Project. URL:http://www.ktl.fi/publications/monica/ hdl/hdlqa.htm.

Middleton A, Fuat A. 2006. Achieving lipid goals in real life: the DISCOVERY-UK study. Br J Cardiol, 13:72-6.

Olsson AG, Istad H, Luurila O, et al; on behalf of the Rosuvastatin Investigators Group. 2002. Effects of rosuvastatin and atorvastatin compared over 52 weeks of treatment in patients with hypercholesterolemia. Am Heart $J, 144: 1044-51$.

Pearson TA, Laurora I, Chu H, et al. 2000. The lipid treatment assessment project (L-TAP): a multi-centre survey to evaluate the percentages of dyslipidemic subjects receiving lipid-lowering therapy and achieving low-density lipoprotein goals. Arch Intern Med, 160:459-67.

Reddy KS, Yusuf S. 1998. Emerging epidemic of cardiovascular disease in developing countries. Circulation, 97:596-601.

Sans S, Kesteloot H, Kromhout D; on behalf of the Task Force. The burden of cardiovascular diseases mortality in Europe. 1997. Task Force of the European Society of Cardiology on cardiovascular mortality and morbidity statistics in Europe. Eur Heart J, 18:1231-48.

Schuster H, Barter PJ, Stender S, et al. 2004. Effects of switching statins on achievement of lipid goals: Measuring Effective Reductions in Cholesterol Using Rosuvastatin Therapy (MERCURY I) study. Am Heart J, 147:705-12. 
Schuster H. 2003. Rosuvastatin - a high effective new 3-hydroxy-3methylglutaryl coenzyme A reductase inhibitor: review of clinical trial data at $10-40 \mathrm{mg}$ doses in dyslipidemic patients. Cardiology, 99:126-39.

Sleight P. 2003. Current opinions in the management of coronary heart disease. Am J Cardiol, 92 (Suppl):4N-8N.

Strandberg TE, Feely J, Sigurdsson EL. 2004. Twelve-week, multicenter, randomized, open-label comparison of the effects of rosuvastatin $10 \mathrm{mg} / \mathrm{d}$ and atorvastatin $10 \mathrm{mg} / \mathrm{d}$ in high-risk adults: A DISCOVERY study. Clin Ther, 26:1821-33.

Thaulow E, Erikssen J, Sandvik L, et al. 1993. Initial clinical presentation of cardiac disease in asymptomatic men with silent myocardial ischemia and angiographically documented coronary artery disease (the Oslo Ischemia Study). Am J Cardiol, 72:629-33.

Thom TJ. 1989. International mortality from heart disease: Rates and trends. Int J Epidemiol, 18 (Suppl I):20-8.

Tunstall-Pedoe H, Kuulasmaa K, Mähönen M, et al. for the WHO MONICA (monitoring trends and determinants in cardiovascular disease) Project. 1999. Contribution of trends in survival and coronary-event rates to changes in coronary heart disease mortality: 10-year results from 37 WHO MONICA Project populations. Lancet, 353:1547-57.
Tunstall-Pedoe H, Kuulasmaa K, Tolonen H, et al. with 64 other contributors for the WHO MONICA Project. 2003. MONICA Monograph and Multimedia Sourcebook. World's largest study of heart disease, stroke, risk factors, and population trends 1979-2002. Geneva: WHO.

Vartianen E, Puska P, Pekkanen J, et al. 1994. Changes in risk factors explain changes in mortality from ischaemic heart disease in Finland. Br Med J, 309:23-7.

Wood D, De Backer G, Faegerman O, et al. 1998. Task Force Report: Prevention of coronary heart disease in clinical practice. Recommendations of the Second Joint Task Force of European and Other Societies on coronary prevention. Eur Heart J, 19:1434-503.

Zhu JR, Tomlinson B, Young MR, et al. 2007. A randomised study comparing the efficacy and safety of rosuvastatin with atorvastatin for achieving lipid goals in clinical practice in Asian patients at high risk of cardiovascular disease (DISCOVERY-Asia study). Curr Med Res Opin, 23:3055-68.

Zijlstra F, Patel A, Jones M, et al. for the PCAT collaboration. 2002. Clinical characteristics and outcome of patients with early $(<2 \mathrm{~h})$, intermediate $(2-4 \mathrm{~h})$ and late $(>4 \mathrm{~h})$ presentation treated by primary coronary angioplasty or thrombolytic therapy for acute myocardial infarction. Eur Heart J, 23:550-57. 


\section{Appendix}

The following centers and investigators (all in Estonia) participated in the trial.

North-Estonia Regional Hospital, Tallinn - T. Laks (National Co-ordinator), R Vettus, M. Zemtsovski, L. Anton, Ü. Planken, L. Kalinina, A. Leht, H. Tupits, P. Rudenko, A. Ambos; Mustamäe Outpatient Clinic, Tallinn - A. Kreis (Principal Investigator, PI), M. Leiner, K. Valkenklau, A. Kund, T. Kivimäe, M. Mäemets, E. Gustavson, E. Nukk, T. Simm; Sütiste Centre, Tallinn - Ü. Kaasik (PI), K. Kender, A. Rosenthal, T. Jürgenson; West-Tallinn Central Hospital, Tallinn - I. Lapidus (PI), H. Kaljusaar, L. Aug, A. Bljumovitš, O. Kolbassova, S. Masik; East-Tallinn Central Hospital - A. Reinold (PI), A. Kork, M. Kadarik, M. Reimand, O. Taaler; Pelgulinna Outpatient Clinic, Tallinn - P. Laan (PI), T. Nurmoja, S. Reinmets; Lasnamäe
Health Centre, Tallinn - I. Loogna (PI), L. Meledina (PI), N. Pantelejeva, S. Ehiloo, J. Ivanov, R. Aivazjan, I. Dmitrieva; Nõmme Family Doctors' Centre, Tallinn - P. Pärnakivi (PI), E. Ehatamm, M. Alba, K. Kuningas, J. Miller, P. Tammist, M. Doroš, T. Oruaas, E. Merilind, K. Merilind, R. Raamat; Keila Family Physicians Centre-M. Võsa (PI); Saue Family Doctors' Centre - A. Mäeorg (PI), A. Soomets; Saku Health Centre - M. Petersen (PI), M. Stern; Kuressaare Health Centre - V. Nemvalts (PI), S. Väli, E. Nurmekivi, T. Tarkin; Narva Outpatient Clinic - O. Averina (PI); Rakvere Centre-L. Slobodtshikova (PI), K. Veidrik, A. Kullerkupp; Tartu Puusepa Centre - Ü. Roostalu (PI), M. Treial, L. Koppel; Gildi Outpatient Clinic, Tartu - H. Loogus (PI), M. Plaks, L. Pilv, S. Saarniit, M. Nirk, M. Peda, L. Pullerits; Elva Family Physician - T. Laasik (PI); Viljandi Outpatient Clinic-E. Keba (PI). 